\title{
Current status of newborn screening for Pompe disease in Japan
}

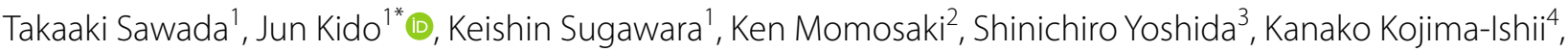 \\ Takahito Inoue ${ }^{5,6}$, Shirou Matsumoto ${ }^{1}$, Fumio Endo ${ }^{1,7}$, Shouichi Ohga ${ }^{4}$, Shinichi Hirose ${ }^{8}$ and \\ Kimitoshi Nakamura ${ }^{1}$
}

\begin{abstract}
Background: Pompe disease is an autosomal recessive inherited metabolic disorder caused by a deficiency of the acid a-glucosidase (GAA). Pompe disease manifests as an accumulation of lysosomal glycogen in the skeletal and heart muscle. We conducted newborn screening (NBS) for Pompe disease in Japan from April 2013 to October 2020 to determine the feasibility and utility of NBS for Pompe disease.

Results: From the 296,759 newborns whose enzyme activity was measured, 107 of which underwent GAA analysis, we found one patient with infantile-onset Pompe disease (IOPD) and seven with potential late-onset Pompe disease (LOPD). We identified 34 pseudodeficient individuals and 65 carriers or potential carriers. The frequency of patients with IOPD was similar to that in the United States, but significantly lower than that in Taiwan. One patient with IOPD underwent early enzyme replacement therapy within a month after birth before presenting exacerbated manifestations, whereas those with potential LOPD showed no manifestations during the follow-up period of six years.

Conclusions: The frequency of IOPD in Japan was similar to that in the United States, where NBS for Pompe disease is recommended. This indicates that NBS for Pompe disease may also be useful in Japan. Therefore, it should be used over a wider region in Japan.
\end{abstract}

Keywords: Pompe disease, Newborn screening, Acid a-glucosidase, GAA, Pseudodeficiency allele, Disease frequency

\section{Background}

Pompe disease, also known as glycogen storage disease type II (OMIM 232300), is an autosomal recessive inherited metabolic disorder caused by a deficiency of the enzyme known as acid $\alpha$-glucosidase (GAA, EC 3.2.1.20/3) that breaks down glycogen in the lysosome, leading to the accumulation of lysosomal glycogen in skeletal and heart muscles [1]. In addition, glycogen accumulates in tissues throughout the body and may cause symptoms in multiple organs, including the

\footnotetext{
${ }^{*}$ Correspondence: kidojun@kuh.kumamoto-u.ac.jp

1 Department of Pediatrics, Graduate School of Medical Sciences,

Kumamoto University, 1-1-1 Honjo, Chuo-ku, Kumamoto City, Kumamoto 860-8556, Japan

Full list of author information is available at the end of the article
}

nervous system [2]. Clinically, two classical phenotypes have been described according to the age of onset: infantile and late-onset types [3]. Patients with infantile-onset Pompe disease (IOPD) exhibit a nearly complete absence of GAA activity and present with hypotonia and hypertrophic cardiomyopathy in early infancy. These patients eventually die of cardiorespiratory failure within the first year of life because of the extensive accumulation of glycogen in skeletal and heart muscles. In contrast, patients with late-onset Pompe disease (LOPD) have a variable residual GAA activity and predominantly manifest skeletal muscle dysfunction but rarely present cardiac muscle dysfunction. Enzyme replacement therapy (ERT) is essential for the treatment of IOPD $[4,5]$. To achieve optimal outcomes, ERT should be started before symptoms clearly manifest and prior to the development of original author(s) and the source, provide a link to the Creative Commons licence, and indicate if changes were made. The images or other third party material in this article are included in the article's Creative Commons licence, unless indicated otherwise in a credit line to the material. If material is not included in the article's Creative Commons licence and your intended use is not permitted by statutory regulation or exceeds the permitted use, you will need to obtain permission directly from the copyright holder. To view a copy of this licence, visit http://creativecommons.org/licenses/by/4.0/. The Creative Commons Public Domain Dedication waiver (http://creativeco mmons.org/publicdomain/zero/1.0/) applies to the data made available in this article, unless otherwise stated in a credit line to the data. 
irreversible damage [6,7]. The early initiation of ERT in patients with IOPD can improve survival rates and quality of life, reduce the need for ventilation, and promote earlier independent walking $[8,9]$.

Newborn screening (NBS) is one of the best approaches for the early diagnosis and treatment of Pompe disease. Asian populations have a high frequency of pseudodeficiency alleles c.1726G $>\mathrm{A}$ and 2065G $>\mathrm{A}$ in $G A A$, which significantly reduce GAA activity [10]. Particularly, in the Japanese population, the frequency of these alleles is estimated to be $3.9 \%$ and $30.5 \%$ in homozygous and heterozygous forms, respectively [11]. Therefore, the presence of pseudodeficiency alleles are major obstacles that have negatively affected NBS for Pompe disease in our previous pilot program, which analyzed 715 Japanese newborns and 18 previously diagnosed patients [11]. Some NBS programs for Pompe disease, including ours, have shown that the combination of GAA enzyme assays using dried-blood spot (DBS) cards and GAA gene mutation analysis could be useful in distinguishing false-positive cases from patients with Pompe disease.

Previously, we conducted a screening program for Pompe disease among 103,204 newborns in the Kumamoto and Fukuoka prefectures in Japan, and we identified no patient with IOPD and only three individuals with potential LOPD [12]. Therefore, in this study, we conducted the program at a larger scale, screening 297,387 newborns from April 2013 to October 2020 by employing a fluorometric enzymatic assay with 4-methylumbelliferyl $\alpha$-D-glucopyranoside (4MU- $\alpha$ Glc) on DBSs to detect GAA activity. We identified a patient with IOPD and detected individuals with potential LOPD. This is the first report of the determination of the frequency of IOPD in Japan through NBS.

\section{Results}

\section{NBS for Pompe disease}

The experimental workflow and the results of our NBS program for Pompe disease are shown in Fig. 1. In total, 297,387 newborns were screened. We established efficient GAA assay methods I to III by modifying the reaction time and buffer composition to achieve multiple high-throughput screening options. In summary, the median GAA activities were 25.0 (interquartile range (IQR), 17.3-33.8) (Fig. 2), 45.4 (31.8-62.5), and $40.0 \mathrm{pmol} \mathrm{h}^{-1}$ disk $^{-1}$ (28.6-53.1) in Methods IIII, respectively (Additional file 1). Next, 316 DBSs whose GAA activities were under the cutoff values ( $<6.5 \mathrm{pmol} \mathrm{h}^{-1}$ disk $^{-1}$ in Method $\mathrm{I} ;<3.5 \mathrm{pmol} \mathrm{h}^{-1}$ disk $^{-1}$ in Methods II, III) were recalled for a second GAA assay. The cutoff value for Method I was set at the 4th percentile in the pilot study, whereas those for Methods II and III were set at the 0.1 percentile.

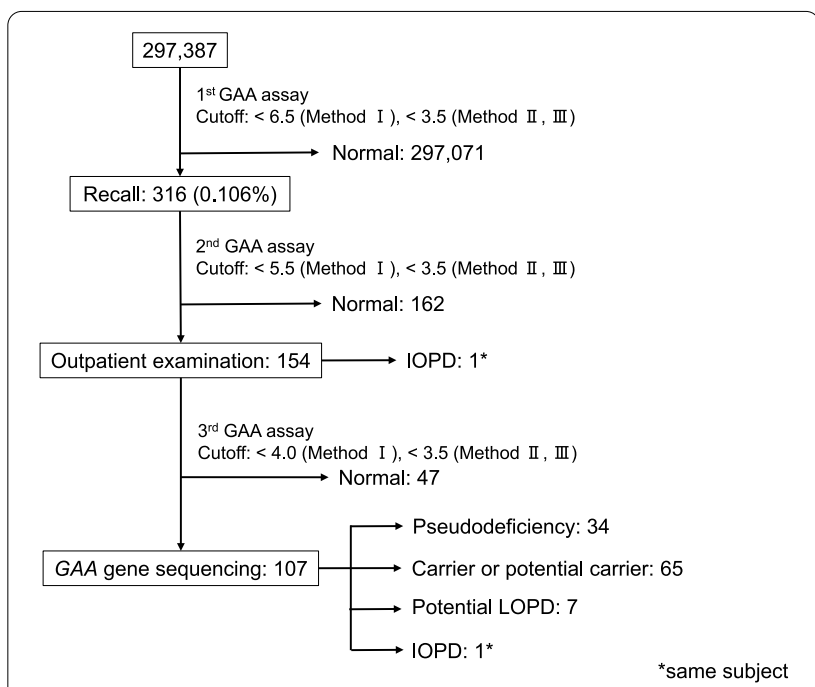

Fig. 1 Flowchart of the newborn screening program for Pompe disease

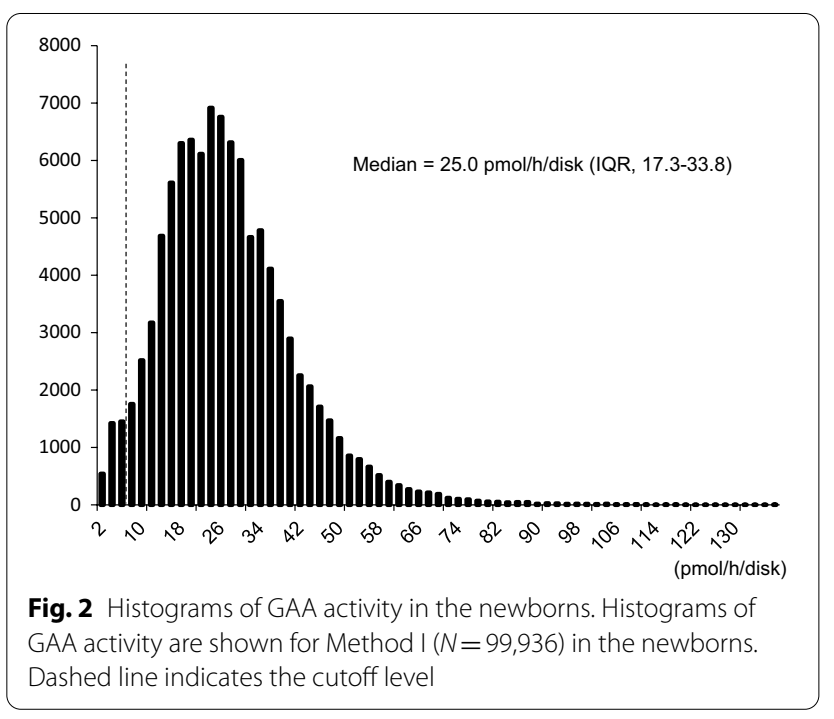

Moreover, 154 newborns whose GAA activities were under the cutoff for the second GAA assay were examined at the outpatient clinic. Physical and biochemical examinations, including that for alanine transaminase, aspartate aminotransferase, lactate dehydrogenase, and creatine kinase $(\mathrm{CK})$, and echocardiogram assessments were performed at referral hospitals. The third GAA assay was then performed. The DBSs of 107 newborns whose GAA activities were under the cutoff for the third GAA assay were subjected to GAA gene sequencing analysis. Overall, we identified one patient with IOPD and seven individuals as potential LOPD patients. 


\section{Detected variants}

The GAA gene is highly polymorphic, and many novel variants are continually being discovered. Based on the Pompe disease GAA variant database [13] (http://www. pompevariantdatabase.nl; Accessed March 3, 2021) and the ClinVar Miner database [14] (https://clinvarminer. genetics.utah.edu/; Accessed March 3, 2021), we identified 910 and 1,170 sequence variations, respectively. Table 1 shows the 78 variants identified from 107 newborns, 71 of which were registered in the Pompe disease $G A A$ variant database [13, 15] or ClinVar Miner. The other seven variants, i.e., c.439G $>$ A (p.G147S), c.539_543delACTTC (p.F181Dfs*6), c.1170delC (p.N390Kfs*2), c.547-27A > G, c.1194+19_1194+20 ins A, c.1552-52C > A, and c.2859G > A (non-coding), were not registered. The last two variants are considered as nonpathogenic according to our previous report [12], whereas the other five are novel. One missense variant, c.439G > A (p.G147S), was predicted by using PolyPhen-2 as "probably damaging." Two variants, c.539_543delACTTC (p.F181Dfs*6) and c.1170delC (p.N390Kfs*2) had frameshift changes and were predicted as pathogenic. The pathogenicity of two intronic variants, c.547-27A > G and c.1194+19_1194+20 insA, are unknown; however, c.547-27A $>\mathrm{G}$ was predicted using the Human Splicing Finder [16] as a "potential alteration of splicing." Therefore, we focused on four variants predicted as disease-associated, namely c.439G > A (p.G147S), c.539_543delACTTC (p.F181Dfs*6), c.1170delC (p.N390Kfs ${ }^{*}$ ), and c.547-27A > G.

Of the 78 variants, 29 were classified as disease-associated (pathogenic or predicted pathogenic variants), and the other 49 were classified as non-pathogenic (polymorphisms or predicted nonpathogenic variants) (Table 1 ). The most common disease-associated variant was c. $752 \mathrm{C}>\mathrm{T}+\mathrm{c} .761 \mathrm{C}>\mathrm{T}$, accounting for 31 alleles $(14.5 \%$, 31/214). Meanwhile, c.752C $>\mathrm{T}$ and c.761C $>\mathrm{T}$ occurred in cis formation [17]; thus, these variants were treated as c.752C $>\mathrm{T}+$ c.761C $>\mathrm{T}$. The second most common disease-associated variant was c.317G > A (p.R106H), which accounted for 10 alleles $(4.7 \%, 10 / 214)$, whereas the third most common was c.1316 T >A (p.M439K), which accounted for seven alleles $(3.3 \%, 7 / 214)$.

\section{Identified individuals with GAA variants}

We detected one individual as IOPD patient (subject ID 140 ), seven as potential LOPD patients (subject IDs 84, $87,93,127,130,131$, and 133), 65 carriers or potential carriers, and 34 with pseudodeficiency alleles (Table 2). A total of 102 of 107 individuals with low GAA activity (95.3\%) had a pseudodeficiency variant, c.[1726G > A; $2065 \mathrm{G}>\mathrm{A}]$.
One patient with IOPD had two pathogenic variants, c.539_543delACTTC (p.F181Dfs*6) and c.1798C > T (p.R600C), and one predicted pathogenic variant, c.54727A > G. The c.539_543delACTTC variant was novel, whereas c. $1798 \mathrm{C}>\mathrm{T}$ has been reported as pathogenic in patients with IOPD [18]. In addition, this patient developed hypotonia, hypertrophic cardiomyopathy, and hyperCKemia (714 IU/L) within a month after birth, and was subjected to ERT in the first month of life. On day 3 of treatment, the hypotonia improved, and the hypertrophic cardiomyopathy improved after 10 weeks. At 7 months of age, this patient had mild hyperCKemia (200-300 IU/L) but had normal psychomotor development.

Seven individuals who presented with more than two disease-associated variants did not develop any signs or symptoms related to Pompe disease (e.g., hypotonia, echocardiographic findings of hypertrophic cardiomyopathy, and hyperCKemia) and, thus, received no treatment. They were classified as potential LOPD patients. Their GAA activities and gene mutations are shown in Table 2. Six individuals had c.752C $>\mathrm{T}+\mathrm{c} .761 \mathrm{C}>\mathrm{T}$. The other variants included c.317G $>$ A (p.R106H), c.1244C $>$ T (p.T415M), c.1857C $>$ G (p.S619R), c.2003A > G (p.Y668C), c.2173C > T (p.R725W), and c.2647-7G > A. Three of these seven individuals (i.e., subject ID 84, 87, and 93) had been previously identified [12] and were subjected to follow-up evaluation. As of February 2021, they remained free from signs or symptoms associated with Pompe disease.

\section{Discussion}

Previously, we have reported the first large-scale newborn screening $(N=103,204)$ for Pompe disease in Japan and identified no IOPD patients and three potential LOPD patients [12]. By October 2020, 297,387 newborns have been screened, and one patient with IOPD and four potential newborns with LOPD were identified. The patient with IOPD was able to undergo early ERT in the first month of life before presenting with exacerbated symptoms.

This screening program demonstrated the effectiveness of NBS for Pompe disease both in Japan and overseas. The frequency of IOPD detected in this program (i.e., 1/296,759) is similar to that in the United States (i.e., California $1 / 226,000$ [19], Illinois $1 / 228,000$ [20], and Pennsylvania $1 / 265,570$ [21]). In contrast, the NBS for Pompe disease in Taiwan identified six patients with IOPD from 402,281 newborns $(1 / 57,000)$ [9]. Although Japan and Taiwan are geographically near, the rate of detection of IOPD pathogenic variants is different. In Taiwan, five of six IOPD patients are homozygous or heterozygous for the same variant c.1935C $>\mathrm{A}$. In 
Table 1 Variants detected in the NBS program for Pompe disease




Table 1 (continued)

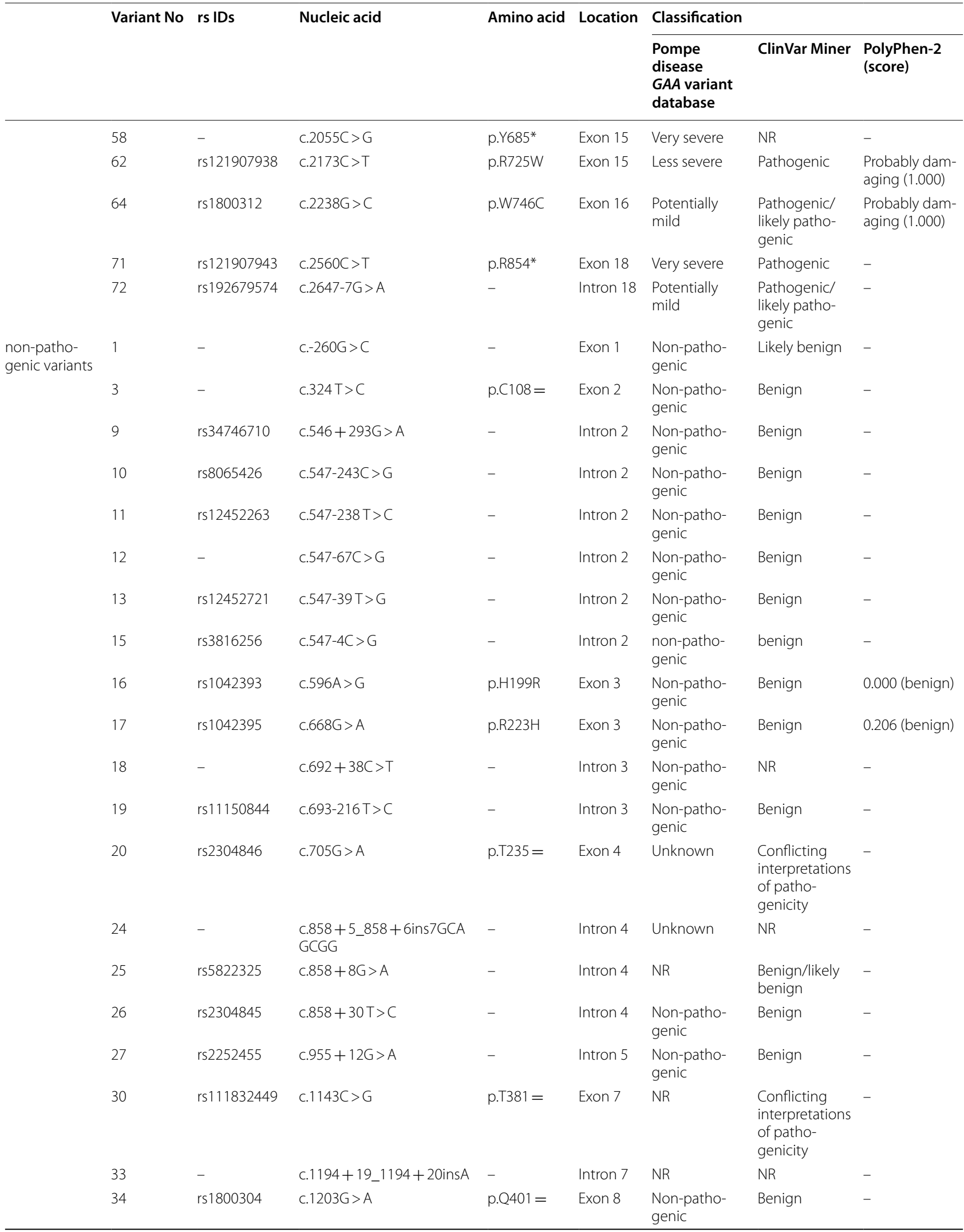


Table 1 (continued)

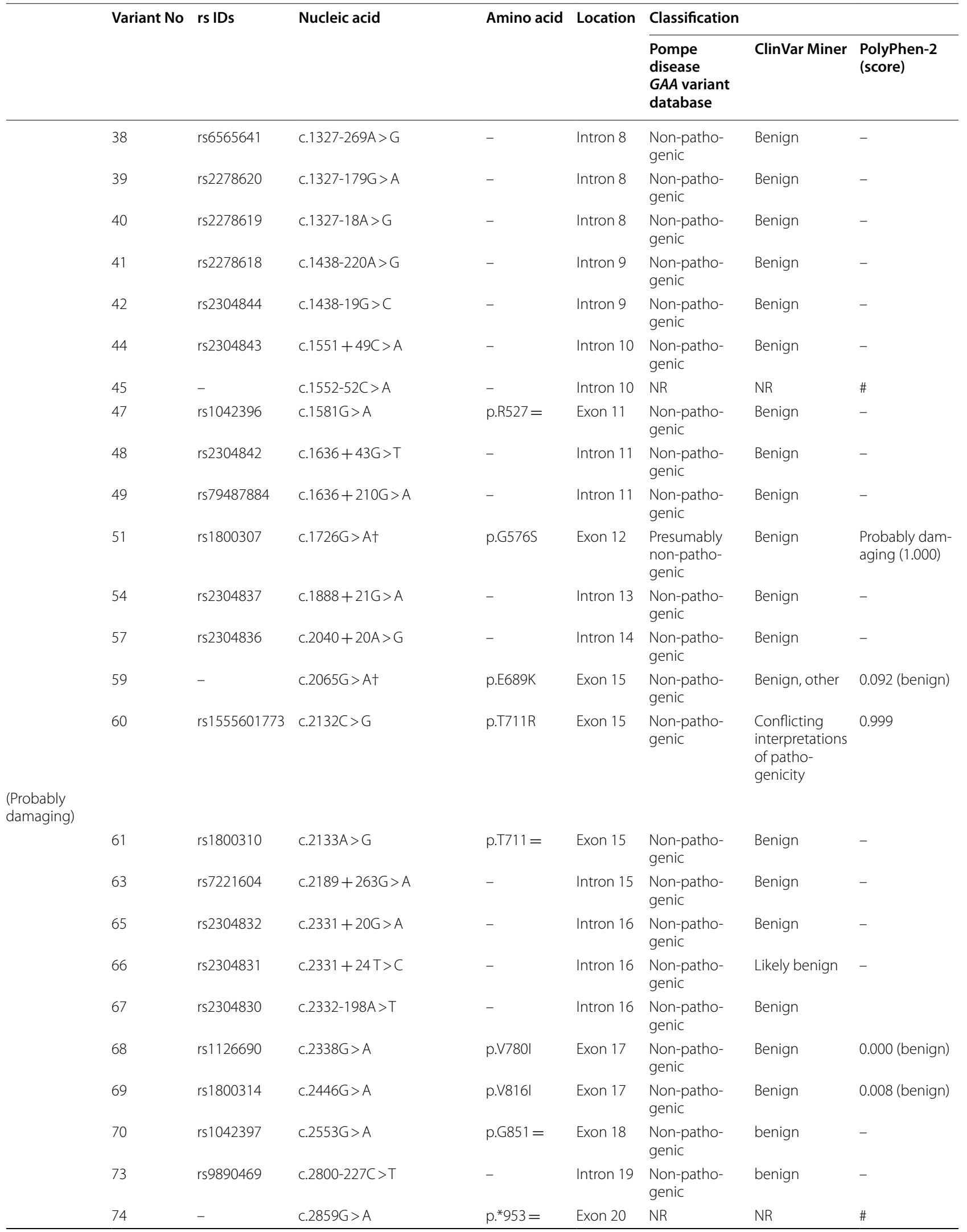


Table 1 (continued)

\begin{tabular}{|c|c|c|c|c|c|c|c|}
\hline \multirow[t]{2}{*}{ Variant No } & \multirow[t]{2}{*}{ rs IDs } & \multirow[t]{2}{*}{ Nucleic acid } & \multirow[t]{2}{*}{ Amino acid } & \multirow[t]{2}{*}{ Location } & \multicolumn{3}{|l|}{ Classification } \\
\hline & & & & & $\begin{array}{l}\text { Pompe } \\
\text { disease } \\
\text { GAA variant } \\
\text { database }\end{array}$ & ClinVar Miner & $\begin{array}{l}\text { PolyPhen-2 } \\
\text { (score) }\end{array}$ \\
\hline 75 & rs1800317 & c.* $3 G>A$ & - & Exon 20 & $\begin{array}{l}\text { Non-patho- } \\
\text { genic }\end{array}$ & Benign & - \\
\hline 76 & rs865903736 & c.*139dup & - & Exon 20 & $N R$ & Likely benign & - \\
\hline 77 & rs8132 & $c^{*} 223 C>T$ & - & Exon 20 & $\begin{array}{l}\text { Non-patho- } \\
\text { genic }\end{array}$ & Benign & - \\
\hline 78 & rs7567 & $c^{*} 419 \mathrm{G}>\mathrm{T}$ & - & Exon 20 & $N R$ & Benign & - \\
\hline
\end{tabular}

$\mathrm{NR}$, not registered

${ }^{\dagger}$ Pseudodeficiency alleles; Human Splicing Finder: "No impact on splicing; \#"Potential alteration of splicing

contrast, our study only detected one individual (No. 141) with the same variant among 107 newborns who underwent $G A A$ sequencing analysis (allele frequency: $0.47 \%$ ) (Table 2). The high frequency of IOPD patients in Taiwan is attributed to the high frequency of allele c.1935C > A, which was most commonly found in IOPD patients in Taiwan and southern China [22-24]. On the other hand, the Missouri program [25] detected more patients with IOPD than our program. Particularly, 10 patients with IOPD were identified from approximately 467,000 newborns (1/46,700). In addition, c.525delT was detected in three alleles, whereas c.1447G $>$ A, c. $1802 \mathrm{C}>\mathrm{T}$, c. $2560 \mathrm{C}>\mathrm{T}$, c. $-32-13 \mathrm{~T}>\mathrm{G}$, and del exon 18 were detected in two alleles. The high frequency of these specific variants may contribute to the high frequency of patients with IOPD.

The IOPD patient identified in this study harbored one pathogenic variant, c.1798C $>\mathrm{T}$ and two predicted pathogenic variants, c.547-27A $>\mathrm{G}$ and c.539_543delACTTC. To date, the c.539_543delACTTC variant is unreported but considered as pathogenic. It contains a stop codon in the amino acid sequence with a frameshift mutation due to a defect in 5 bases (Additional file 2). On the other hand, c.1798C $>\mathrm{T}$ is a known pathogenic variant [18] and is common in Japanese patients with IOPD [26]. However, the frequency of this allele in this study was $0.9 \%(2 / 214)$, indicating that it is not a hotspot mutation. Human Splicing Finder, which is a tool to predict the effects of mutations on splicing signals or to identify splicing motifs, predicted c.547$27 \mathrm{~A}>\mathrm{G}$ as "potential alteration of splicing." However, the actual pathogenicity of c.547-27A $>\mathrm{G}$ is unknown. Moreover, as the parents of the patient had not been sequenced for the GAA gene, which variant was in which allele remains unclear. However, we predicted that the patient has compound heterozygosity for the c.539_543delACTTC and c.1798C > T variants.
Of the seven individuals diagnosed with potential LOPD in this study, six had c. $752 \mathrm{C}>\mathrm{T}+\mathrm{c} .761 \mathrm{C}>\mathrm{T}$ (five heterozygous and two homozygous). c. $752 \mathrm{C}>\mathrm{T}+\mathrm{c} .761 \mathrm{C}>\mathrm{T}$ is one of the most frequently detected variants in NBS (allele frequency: 14.5\% 31/214). In Taiwan, five of the 13 individuals with potential LOPD were homozygous or heterozygous [27]. The pathogenicity of this variant remains controversial. Chien et al. [28] reported a female patient with $\mathrm{c} .752 \mathrm{C}>\mathrm{T}+\mathrm{c} .761 \mathrm{C}>\mathrm{T}$, harboring a potentially pathogenic variant (c.1958C $>$ A) with compound heterozygozity. She presented with proximal muscle weakness without elevated blood CK and urinary glucose tetrasaccharide (Glc4) levels. Individuals with this variant require long-term follow-up to determine variant pathogenicity. Notably, the pathogenic variant c.-32-13T $>$ G, which is frequently detected in patients with LOPD in Europe and the United States [29], was not detected in our screening program.

The total recall rate in this program was $0.1 \%$, which was approximately five times higher than that of the United States [19, 21]. We attribute the high falsepositive rate to the high frequency of the pseudodeficiency variant c. $[1726 \mathrm{G}>\mathrm{A} ; 2065 \mathrm{G}>\mathrm{A}]$ in East Asia. Our results demonstrated that most of the 107 newborns who underwent genetic analysis had homozygous or heterozygous pseudodeficiency variants (Table 2). A false-positive result constitutes an economic burden and causes subsequent psychological distress on patients and their families. To reduce the false-positive rate, it is necessary to distinguish between pseudodeficient subjects and Pompe disease patients at the time of screening before recall. Liao et al. reported that measuring enzyme activity using tandem mass spectrometry can reduce the incorrect inclusion of individuals with pseudodeficiency among false-positive results [30]. On the other hand, in Illinois, where NBS for Pompe disease was performed by measuring enzyme activity 


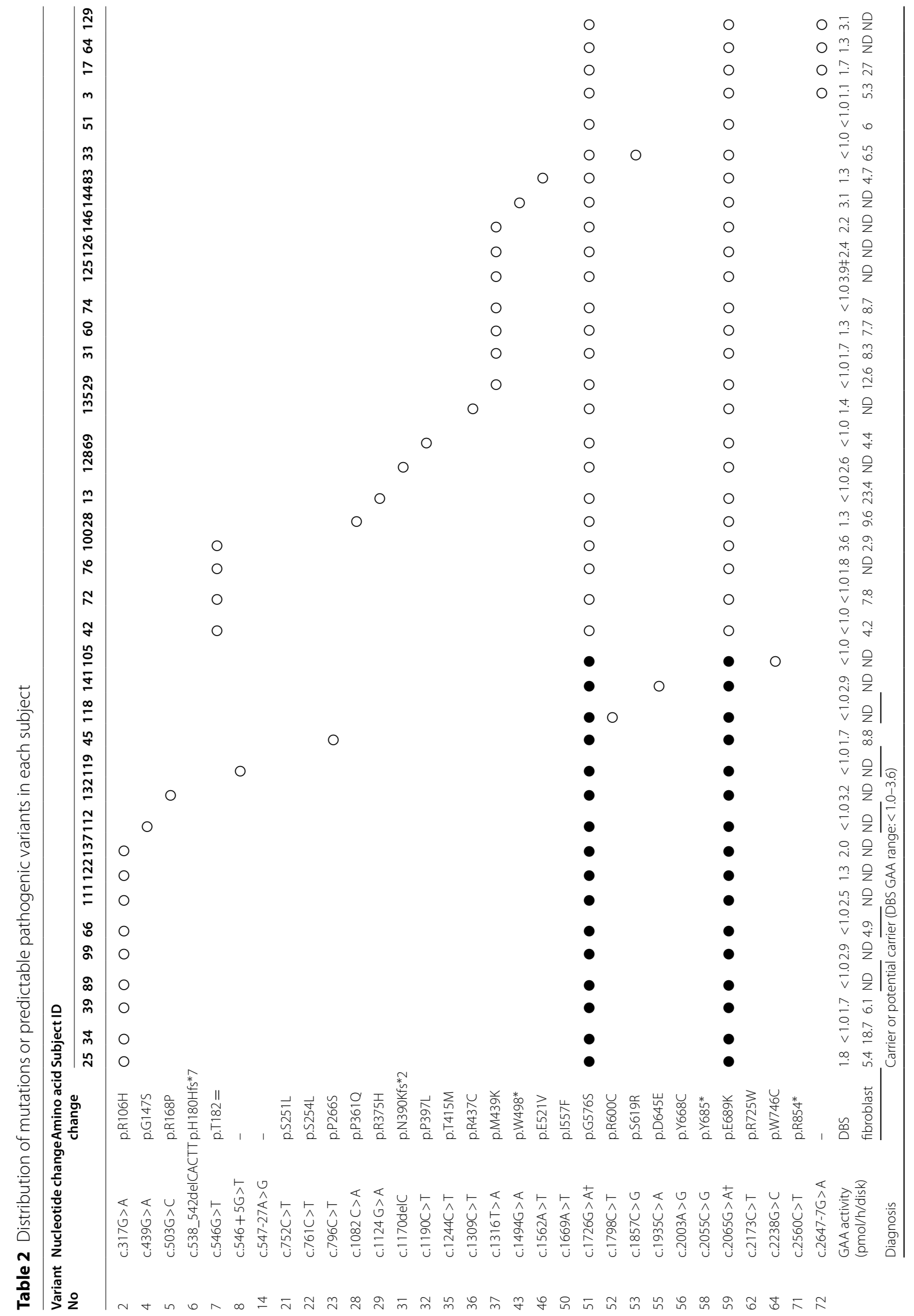




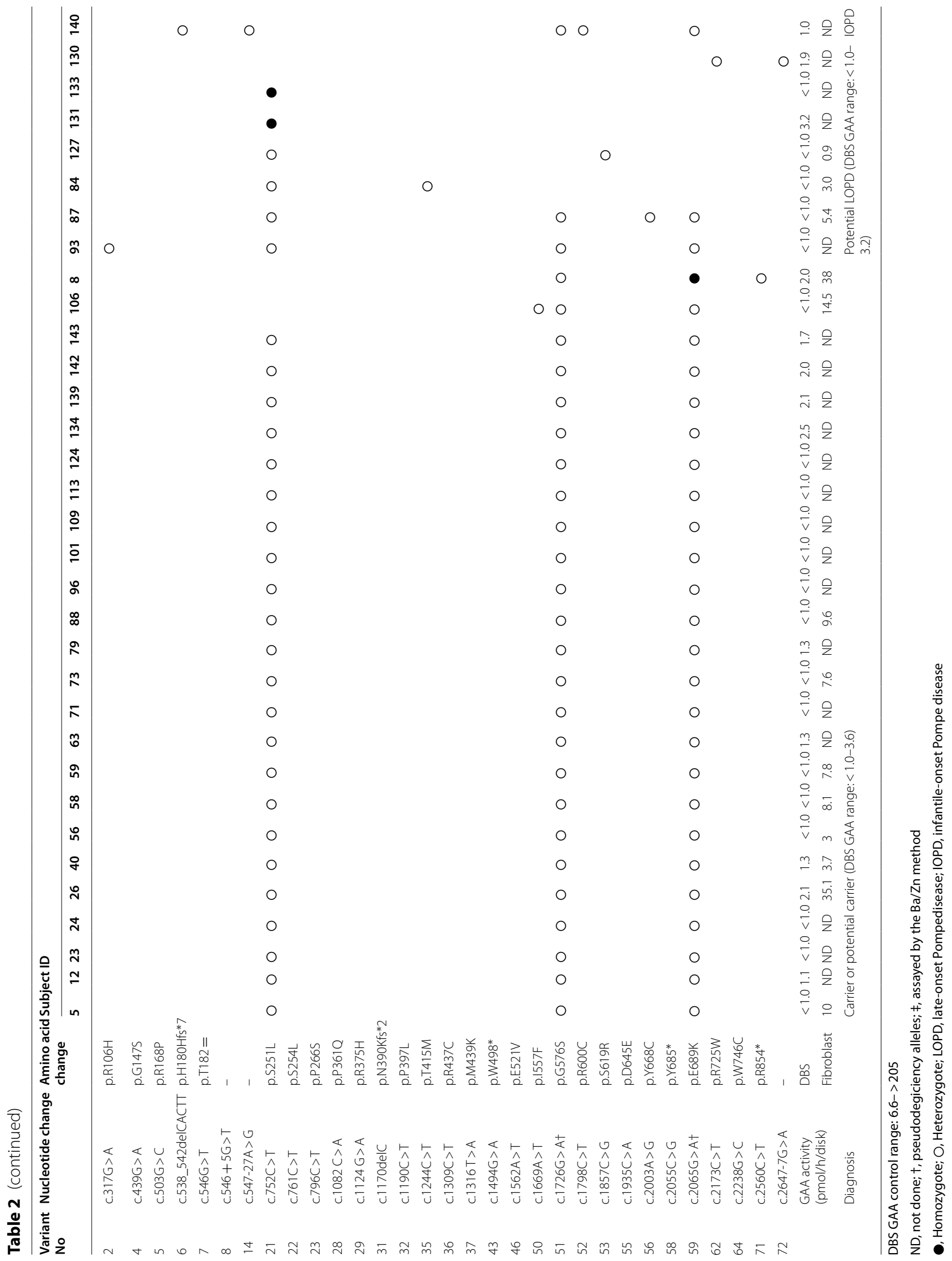


using tandem mass spectrometry, 39 of the 395 individuals who presented with positive screening results were pseudodeficient, and all of them were of Asian descent [20]. Therefore, it may be difficult to distinguish pseudodeficiency only by measuring enzyme activity using tandem mass spectrometry. Additional GAA sequencing analysis by next-generation sequencing (NGS) using DBS prior to recall may be effective in reducing the false-positive rate [31]. Furthermore, some studies propose using microRNA (miR-133a) as a biomarker for Pompe disease $[32,33]$ as it can distinguish patients with IOPD from those with LOPD, indicating its value as a tool for diagnosis and the monitoring of therapeutic effects [33].

This study has some limitations. First, as NBS was conducted in limited areas only, which constitutes approximately $5.4 \%$ of the entire population, our results do not reflect the frequency of disease-associated variants throughout Japan. To solve this problem, it is necessary to conduct NBS for Pompe disease throughout Japan. Second, the combination of the enzyme assay and DNA analysis still did not definitively diagnose LOPD patients manifesting no clinically-recognized symptoms. Currently, we are conducting follow-up assessments on individuals with potential LOPD and monitoring their blood CK levels and muscle symptoms to determine if they have LOPD. Additionally, the urinary Glc4 level may be a useful biomarker for Pompe disease [34, 35]. Thus, urinary Glc4 measurements may be considered in future screenings for LOPD.

\section{Conclusions}

We report the current results of NBS for Pompe disease in Japan among 296,759 newborns and identified one patient with IOPD and seven individuals with potential LOPD. The frequency of IOPD in Japan was similar to that in the United States, where the Recommended Uniform Screening Panel (RUSP) suggests NBS for Pompe disease; this indicates that newborn screening for Pompe disease may also be useful in Japan. The IOPD patient immediately underwent ERT within a month after birth before presenting exacerbated manifestations, whereas the seven individuals with potential LOPD underwent long-term follow-up and showed no manifestations. Long-term follow-up from the neonatal period may allow treatment with ERT to begin before irreversible symptoms progress and may, therefore, improve the quality of life of patients. In the future, inter-racial marriage and migration may increase the frequency of Pompe disease. Therefore, NBS for Pompe disease should be extended over a wider region in Japan.

\section{Materials and methods}

\section{Study population and sample collection}

The study population consisted of 297,387 newborns from Kumamoto and Fukuoka prefectures between April 2013 and October 2020. Dried-blood spot (DBS) samples were prepared in each maternity clinic or obstetric department using a heel prick procedure 4-6 days after birth for newborn mass screening across all municipalities. After blotting with blood spots (Toyo Roshi Kaisha, Ltd., Tokyo, Japan), the filter paper was dried for at least $4 \mathrm{~h}$ at room temperature (i.e., $20 \pm 5{ }^{\circ} \mathrm{C}$ ), and the samples were sent to the Newborn Screening Center at KM Biologics Co., Ltd. (Kumamoto, Japan), where publiclyfunded newborn mass screening was conducted, within 1 week of collection. After analysis, the DBSs after testing were transferred to Kumamoto University to assay GAA activity.

\section{NBS program for Pompe disease}

Our proposed NBS for Pompe disease utilizing GAA assays on DBSs involves three steps (Fig. 1). First, DBS samples whose GAA activity was under the cutoff value $\left(<6.5 \mathrm{pmol} \mathrm{h}^{-1}\right.$ disk $^{-1}$ in Method I; $<3.5 \mathrm{pmol} \mathrm{h}^{-1}$ disk $^{-1}$ in Methods II, III) were recalled, and DBSs were prepared again for a second GAA assay. Second, newborns whose GAA activity was under the cutoff value were referred to the hospital within two months for clinical examination, and physical and biochemical assays were performed to confirm the symptomatic signs of IOPD. The new DBS samples were subjected to hemoglobin precipitation using the $\mathrm{Ba} / \mathrm{Zn}$ method to considerably improve the 4MU fluorescence intensity and a third GAA assay was also performed. Finally, GAA gene sequencing was performed in newborns whose GAA activity was under the cutoff value following the third GAA assay to confirm the presence of GAA gene variants. Additionally, the GAA activity of the fibroblasts of the newborns was measured between April 2013 and November 2016 [12]. The results of the first GAA assay was acquired 1-2 weeks after birth; the second GAA assay, within 4 weeks after birth; clinical examination, within 2 months after birth; GAA gene analysis and final diagnosis, up to 6 months after birth.

\section{GAA assay \\ Method I}

GAA assays on DBSs and fibroblasts were performed as previously described [12]. Briefly, one disk $(3.2 \mathrm{~mm}$ in diameter) was punched from DBS cards and placed into a well of a 96-well clear microwell plate (Corning, NY, USA) with $100 \mu \mathrm{L}$ of $0.8 \mathrm{mM}$ citrate in $24 \mathrm{mM}$ potassium phosphate buffer $(\mathrm{pH}$ 6.0) containing $0.1 \%$ Triton $\mathrm{X}-100$ for $1 \mathrm{~h}$ at room temperature with gentle mixing. In a 96-well black microwell-plate (PerkinElmer, Waltham, 
MA, USA), a $20 \mu \mathrm{L}$ aliquot of the extract was then added to $40 \mu \mathrm{L}$ of $2.0 \mathrm{mM} 4 \mathrm{MU}-\alpha$ Glc in $0.12 \mathrm{M}$ citrate $/ 0.15 \mathrm{M}$ potassium phosphate buffer ( $\mathrm{pH} 4.0$ ) containing $4.5 \mu \mathrm{M}$ acarbose, incubated at $37{ }^{\circ} \mathrm{C}$ for $24 \mathrm{~h}$, and quenched by adding $190 \mu \mathrm{L}$ of $0.2 \mathrm{M}$ glycine/ $\mathrm{NaOH}$ buffer ( $\mathrm{pH}$ 10.7) containing $0.1 \%$ Triton X-100 and $0.2 \%$ SDS to measure fluorescence intensity.

For the $\mathrm{Ba} / \mathrm{Zn}$ method, a 3.2-mm diameter disk was placed in a $1.5 \mathrm{~mL}$ reaction tube with $60 \mu \mathrm{L}$ of $0.12 \mathrm{M}$ citrate/0.15 M potassium phosphate buffer ( $\mathrm{pH} 4.0$ ) containing $2.0 \mathrm{mM} 4 \mathrm{MU}-\alpha \mathrm{Glc}$ and $3.0 \mu \mathrm{M}$ acarbose and gently mixed for $10 \mathrm{~min}$ at room temperature. The reaction mixture was incubated at $37{ }^{\circ} \mathrm{C}$ for $24 \mathrm{~h}$, added with 30 $\mu \mathrm{L}$ of $0.15 \mathrm{M}$ barium hydroxide, vortexed, and further incubated at room temperature for $5 \mathrm{~min}$. Then, $30 \mu \mathrm{L}$ of $0.15 \mathrm{M}$ zinc sulfate was added, and the tubes were mixed by vortexing, incubated for $10 \mathrm{~min}$ at room temperature, and centrifuged for $5 \mathrm{~min}$ at $12,000 \mathrm{rpm}$ and $5{ }^{\circ} \mathrm{C}$. Finally, $90 \mu \mathrm{L}$ of the supernatant was transferred to a 96-well black microwell plate, and $160 \mu \mathrm{L}$ of $0.4 \mathrm{M}$ glycine $/ \mathrm{NaOH}$ buffer ( $\mathrm{pH} 10.7$ ) containing $0.1 \%$ Triton X-100 was added to measure fluorescence intensity. Stock solutions of 0 , $6.25,12.5,25,50$, and $100 \mu \mathrm{M}$ 4-methylumbelliferone (4MU) in $20 \mathrm{mM}$ sodium phosphate buffer ( $\mathrm{pH} 7.0$ ) were used for standardization of the liberated 4MU concentration. Enzyme activity was expressed as pmol of 4MU released per hour per disk $\left(\mathrm{pmol} \mathrm{h}^{-1}\right.$ disk $\left.^{-1}\right)$. Each assay was performed in duplicate.

\section{Method II}

Method II for multiple assays was developed in collaboration with KM Biologics Co., Ltd. (see details at JP6360848B) and implemented in December 2016. Briefly, a single 3.2-mm diameter disk punched from DBSs was incubated in the well of a 96-well clear microwell plate (Corning, NY, USA) with $100 \mu \mathrm{L}$ of $5 \mathrm{mM}$ $\mathrm{MgCl}_{2}, 0.5 \mathrm{mM}$ dithiothreitol, $0.05 \% \mathrm{NaN}_{3}$, and $0.1 \%$ Triton X-100 in $0.8 \mathrm{mM}$ citrate $/ 24 \mathrm{mM}$ potassium phosphate buffer ( $\mathrm{pH}$ 6.0) for $1 \mathrm{~h}$ at room temperature with gentle mixing. A 20- $\mu \mathrm{L}$ aliquot of the extract was added to $40 \mu \mathrm{L}$ of $2.0 \mathrm{mM} 4 \mathrm{MU}-\alpha$ Glc in $0.12 \mathrm{M}$ citrate/0.15 M potassium phosphate buffer ( $\mathrm{pH} 4.0$ ) containing $4.5 \mu \mathrm{M}$ acarbose in a 96-well black microwell-plate (PerkinElmer, Waltham, MA, USA). The reaction mixture was incubated at $37^{\circ} \mathrm{C}$ for $4 \mathrm{~h}$ and quenched by adding $200 \mu \mathrm{L}$ of $0.3 \mathrm{M}$ glycine/ $\mathrm{NaOH}$ buffer (pH 10.6) containing $10 \mathrm{mM}$ EDTA to measure fluorescence intensity.

\section{Method III}

Method III for more high-throughput assays was also developed in collaboration with KM Biologics Co., Ltd. (see details at P2017-245523) and implemented in February 2019. A single $3.2-\mathrm{mm}$ diameter disk punched from DBSs was incubated in the wells of a 96-well clear microwell plate (Corning, NY, USA) with $200 \mu \mathrm{L}$ of $38 \mathrm{mM} \mathrm{KCl}, 5 \mathrm{mM} \mathrm{MgCl}_{2}, 0.05 \% \mathrm{NaN}_{3}$, and $0.1 \%$ Triton $\mathrm{X}-100$ in $5 \mathrm{mM}$ sodium acetate buffer (pH 5.2) for $1 \mathrm{~h}$ at room temperature with gentle mixing. A $20-\mu \mathrm{L}$ aliquot of the extract was added to $40 \mu \mathrm{L}$ of $2.0 \mathrm{mM} 4 \mathrm{MU}-\alpha \mathrm{Glc}$ in $0.12 \mathrm{M}$ citrate $/ 0.15 \mathrm{M}$ potassium phosphate buffer $(\mathrm{pH} 4.0)$ containing $4.5 \mu \mathrm{M}$ acarbose in a 96-well black microwell-plate (PerkinElmer, Waltham, MA, USA). The reaction mixture was incubated at $38^{\circ} \mathrm{C}$ for $3 \mathrm{~h}$, and the reaction was stopped by adding $200 \mu \mathrm{L}$ of $0.3 \mathrm{M}$ glycine/ $\mathrm{NaOH}$ buffer (pH 10.6) containing $10 \mathrm{mM}$ EDTA to measure fluorescence intensity.

\section{GAA assay of fibroblasts}

GAA assays of fibroblasts were conducted between April 2013 and November 2016. Briefly, fibroblasts were collected from a skin biopsy and cultured under standard conditions in Dulbecco's modified Eagle's medium with $10 \%$ fetal calf serum and antibiotics $(50 \mathrm{kU} / \mathrm{L}$ penicillin and $50 \mathrm{mg} / \mathrm{L}$ streptomycin). After growing to $100 \%$ confluence, fibroblasts were harvested and washed with phosphate-buffered saline. The cell pellet was stored at $-80{ }^{\circ} \mathrm{C}$ until use. Fibroblasts $\left(2\right.$ to $4 \times 10^{6}$ cells) were homogenized in $150 \mu \mathrm{L}$ of water using sonication on ice, and $10 \mu \mathrm{L}$ of the cell homogenate was added to $40 \mu \mathrm{L}$ of the substrate solution containing $2.0 \mathrm{mM} 4 \mathrm{MU}-\alpha \mathrm{Glc}$ in $0.12 \mathrm{M}$ citrate in $0.15 \mathrm{M}$ potassium phosphate buffer $(\mathrm{pH}$ 4.0) containing $3.75 \mu \mathrm{M}$ acarbose (final concentration: $3.0 \mu \mathrm{M})$ in a well of a 96-well black microwell-plate. The reaction mixture was incubated at $37^{\circ} \mathrm{C}$ for $1 \mathrm{~h}$, and the reaction was stopped by the addition of $200 \mu \mathrm{L}$ of $0.2 \mathrm{M}$ glycine $/ \mathrm{NaOH}$ buffer $(\mathrm{pH}$ 10.7) containing $0.1 \%$ Triton X-100 to measure fluorescence intensity, with blank correction. A stock solution of $250 \mu \mathrm{M} 4 \mathrm{MU}$ in $20 \mathrm{mM}$ sodium phosphate buffer ( $\mathrm{pH}$ 7.0) was used for calibration of the liberated 4MU concentration. Enzyme activity was expressed as nanomoles of 4MU released per hour per milligram of cellular protein $\left(\mathrm{nmol} \mathrm{h} \mathrm{h}^{-1} \mathrm{mg}^{-1}\right.$ protein). Each assay was performed in duplicate.

\section{Chemicals and reagents}

$4 \mathrm{MU}-\alpha$ Glc and $4 \mathrm{MU}$ were obtained from Sigma-Aldrich Co. LLC (Tokyo, Japan). Acarbose, barium hydroxide, citric acid monohydrate, dipotassium hydrogenphosphate, disodium hydrogenphosphate 12-water, dithiothreitol, magnesium chloride hexahydrate, sodium azide, sodium dodecyl sulfate, sodium hydrate, Triton X-100, and zinc sulfate were obtained from FUJIFILM Wako Pure Chemical Corporation (Osaka, Japan). Glycine and potassium chloride were obtained from Nacalai Tesque, Inc. (Kyoto, Japan). EDTA was obtained from Dojindo Laboratories (Kumamoto, Japan). 


\section{GAA sequencing using NGS}

GAA sequencing using NGS was conducted as described previously [36]. Briefly, genomic DNA was extracted from total blood using a Gentra Puregene Blood Kit (Qiagen, Hilden, Germany) and stored at $-80{ }^{\circ} \mathrm{C}$ until use. The 22-kbp region, including the $G A A$, was amplified by dividing the genomic DNA into three fragments using long-range polymerase chain reaction (Additional file 2: Fig. S2) with DNA polymerase (KOD FX; Toyobo, Osaka, Japan) on a Veriti Thermal Cycler (Applied Biosystems, Foster City, CA, USA). PCR products were purified using an Agencourt AMP XP PCR Purification Kit (Beckman Coulter, Brea, CA, USA) and quantified with a Qubit dsDNA HS Assay Kit (Life Technologies, Carlsbad, CA, USA) using a Qubit 2.0 Fluorometer (Life Technologies). Simultaneous fragmentation of PCR products and adaptor ligation were performed using a Nextera XT Kit (Illumina, San Diego, CA, USA). Indexed DNA was purified using an Agencourt AMP XP PCR Purification Kit (Beckman Coulter). Each library was validated using High Sensitivity D1000 ScreenTape (Agilent Technologies, Santa Clara, CA, USA) with an Agilent 2200 TapeStation and quantified using a Qubit dsDNA HS Assay Kit with a Qubit 2.0 Fluorometer to allow for library normalization. Sequencing was performed with a MiSeq Reagent Kit v3 on MiSeq sequencer (Illumina) using the "pairedend" sequencing run method. Data were aligned to target sequences on the human reference genome sequence using the MiSeq Reporter software (Illumina). Sequence data analysis, mapping, and variant calling were streamlined using MiSeq Reporter v2 (Illumina). Briefly, reads were aligned to the reference sequence from $80,101,882$ to $80,123,207$ of the genome sequence of chromosome 17 (NC_000017.11) using bwa-0.6.1. Single-nucleotide polymorphism and insertion/deletion identifications were performed using the Genome Analysis Toolkit (GATK v1.6; Broad Institute, Cambridge, MA, USA), and visualization was performed using IGV_2.3.40 (Broad Institute).

\section{$G A A$ resequencing using the Sanger method}

Variants detected in the GAA gene using NGS were re-sequenced using the Sanger method [13]. Briefly, a region including the variant was amplified using PCR with an appropriate set of primers. PCR products were sequenced on an ABI3500xl auto sequencer (Applied Biosystems) and analyzed using Sequencher 5.0 (Gene Codes Corporation, Foster City, CA, USA).

\section{Mutation analysis of the variants}

The mRNA reference sequence (RefSeq) NM_000152.4 was used, whereby the "A" nucleotide of the ATG codon at nucleotide position 398 of the RefSeq constituted +1 numbering of the cDNA sequence. The ATG codon was also represented as +1 for amino acid numbering as set forth by the GAA preprotein sequence NP_000143.2. Mutation nomenclature followed the guidelines established by the Human Genome Variation Society (http:// varnomen.hgvs.org/). The Pompe disease GAA variant database [13] (http://www.pompevariantdatabase. nl; Accessed March 3, 2021) and the ClinVar Miner [14] (https://clinvarminer.genetics.utah.edu/i Accessed March 3, 2021) were to classify each variant. PolyPhen-2 [37] (http://genetics.bwh.harvard.edu/pph2; Accessed March 3, 2021) was used to predict the potential effect of an amino acid alteration on the function of GAA. The online bioinformatics tool, Human Splicing Finder [16] (http://www.umd.be/HSF3/; Accessed March 3, 2021) was used to estimate the effects of mutations on splicing signals.

\section{Abbreviations}

GAA: Acid a-glucosidase; NBS: Newborn screening; IOPD: Infantile-onset Pompe disease; LOPD: Late-onset Pompe disease; ERT: Enzyme replacement therapy; DBSs: Dried blood spots; 4MU-aGlc: 4-Methylumbelliferyl a-Dglucopyranoside; IQR: Interquartile range; CK: Creatine kinase; Glc4: Glucose tetrasaccharide; NGS: Next-generation sequencing; 4MU: 4-Methylumbelliferone; RefSeq: Reference sequence.

\section{Supplementary Information}

The online version contains supplementary material available at https://doi. org/10.1186/s13023-021-02146-z.

Additional file 1: Fig. S1. Histograms of acid a-glucosidase (GAA) activity in the newborns. Histograms of GAA activity are shown for (a) Method II $(N=113,642)$ and $(b)$ Method III $(N=82,208)$ in the newborns. Dashed line indicates the cutoff level.

Additional file 2: Fig. S2. Frameshift variant, c.539_543delACTTC. It contains a stop codon in the amino acid sequence with a frameshift mutation due to a defect in 5 bases.

Additional file 3: Fig. S3. Long-range PCR of GAA gene. The broad black bars and narrow black bars indicate exons and introns, respectively; the horizontal black bar and blue bars indicate the GAA gene, and pairs of primers, respectively. The ATG codon is represented as +1 for amino acid numbering as per the GAA preprotein sequence NP_000143.2

\section{Acknowledgements}

We are grateful to Ms. Fumiko Nozaki, Ms. Naomi Yano, Ms. Ayuko Tateishi, Ms. Emi Harakawa, Ms. Yasuyo Sakamoto, Ms. Hiroko Nasu, and Ms. Matsumi Harada for providing technical support related to this study.

\section{Authors' contributions}

$\mathrm{TS}, J K, K S$, and $K N$ were responsible for the design of the research. TS, JK, KS, KM, SY, KK-I, TI, SM, FE, SO and SH contributed to measurements and data collection. TS, JK, KS, SY, SM and FE checked and analyzed the data. TS, JK and KS wrote the manuscript. JK and KN supervised this study. All authors read and approved the final manuscript for submission. All authors have agreed both to be personally accountable for the author's own contributions and to ensure that questions related to the accuracy or integrity of any part of the work, even ones in which the author was not personally involved, are appropriately investigated, resolved, and the resolution documented in the literature. 


\section{Funding}

This study was supported in part by a Health and Labor Sciences Research Grant for Research on Rare and Intractable Diseases from the Ministry of Health, Labour and Welfare, Japan (grant number JPMH2OFC1025); a Grantin-Aid for Practical Research Project for Rare/Intractable Diseases from the Japan Agency for Medical Research and Development (AMED; grant numbers JP19ek0109276, JP20ek0109482); and a Grant-in-Aid for Scientific Research from the Ministry of Education, Culture, Sports, Science, and Technology, Japan (Japan Society for the Promotion of Science [JSPS] KAKENHI: grant number JP20K08207).

\section{Availability of data and materials}

The datasets used and/or analysed during the current study are available from the corresponding author on reasonable request.

\section{Declarations}

Ethics approval and consent to participate

This study was approved by the Ethics Committee of Kumamoto University (approval no. 1537). Written informed consent was obtained from the parents or legal guardians of newborns.

\section{Consent for publication}

Not applicable.

\section{Competing interests}

The authors declare that they have no competing interests.

\begin{abstract}
Author details
${ }^{1}$ Department of Pediatrics, Graduate School of Medical Sciences, Kumamoto University, 1-1-1 Honjo, Chuo-ku, Kumamoto City, Kumamoto 860-8556, Japan. ${ }^{2}$ Kumamoto-Ashikita Medical Center for Disabled Children, Kumamoto, Japan. ${ }^{3}$ KM Biologics Co., Ltd., Kumamoto, Japan. ${ }^{4}$ Department of Pediatrics, Graduate School of Medical Sciences, Kyushu University, Fukuoka, Japan. ${ }^{5}$ Department of Pediatrics, School of Medicine, Fukuoka University, Fukuoka, Japan. ${ }^{6}$ Department of Pediatrics, Fukuoka University Chikushi Hospital, Fukuoka, Japan.

${ }^{7}$ Kumamoto-Ezuko Medical Center for Disabled Children, Kumamoto, Japan.

${ }^{8}$ General Medical Research Center, School of Medicine, Fukuoka University, Fukuoka, Japan.
\end{abstract}

Received: 6 May 2021 Accepted: 28 November 2021

Published online: 18 December 2021

\section{References}

1. Martiniuk F, Mehler M, Pellicer A, Tzall S, La Badie G, Hobart C, et al. Isolation of a cDNA for human acid a-glucosidase and detection of genetic heterogeneity for mRNA in three a-glucosidase-deficient patients. Proc Natl Acad Sci U S A. 1986;83:9641-4.

2. Chan J, Desai AK, Kazi ZB, Corey K, Austin S, Hobson-Webb LD, et al. The emerging phenotype of late-onset Pompe disease: a systematic literature review. Mol Genet Metab. 2017;120:163-72.

3. Kishnani PS, Steiner RD, Bali D, Berger K, Byrne BJ, Case LE, et al. Pompe disease diagnosis and management guideline. Genet Med. 2006:8:267-88.

4. Kishnani PS, Corzo D, Nicolino M, Byrne B, Mandel H, Hwu WL, et al. Recombinant human acid [alpha]-glucosidase: major clinical benefits in infantile-onset Pompe disease. Neurology. 2007;68:99-109.

5. van der Ploeg AT, Clemens PR, Corzo D, Escolar DM, Florence J, Groeneveld GJ, et al. A randomized study of alglucosidase alfa in late-onset Pompe's disease. N Engl J Med. 2010;362:1396-406. https://doi.org/10. 1056/NEJMoa0909859.

6. Kishnani PS, Corzo D, Leslie ND, Gruskin D, Van Der Ploeg A, Clancy JP, et al. Early treatment with alglucosidase alfa prolongs long-term survival of infants with Pompe disease. Pediatr Res. 2009;66:329-35. https://doi.org/10.1203/PDR.0b013e3181b24e94.

7. Prater SN, Banugaria SG, Dearmey SM, Botha EG, Stege EM, Case LE, et al. The emerging phenotype of long-term survivors with infantile Pompe disease. Genet Med. 2012;14:800-10.
8. Chien YHYH, Lee NCNCNC, Thurberg BL, Chiang SCSC, Zhang XK, Keutzer J, et al. Pompe disease in infants: improving the prognosis by newborn screening and early treatment. Pediatrics. 2009;124:e1116-25. https://doi. org/10.1542/peds.2008-3667.

9. Yang C-F, Liu H-C, Hsu T-R, Tsai F-C, Chiang S-F, Chiang C-C, et al. A largescale nationwide newborn screening program for pompe disease in Taiwan: towards effective diagnosis and treatment. Am J Med Genet Part A. 2014;164:54-61. https://doi.org/10.1002/ajmg.a.36197.

10. Kroos MA, Mullaart RA, Van Vliet L, Pomponio RJ, Amartino H, Kolodny EH, et al. p.[G576S; E689K]: pathogenic combination or polymorphism in Pompe disease? Eur J Hum Genet. 2008;16:875-9.

11. Kumamoto S, Katafuchi T, Nakamura K, Endo F, Oda E, Okuyama T, et al. High frequency of acid a-glucosidase pseudodeficiency complicates newborn screening for glycogen storage disease type II in the Japanese population. Mol Genet Metab. 2009;97:190-5.

12. Momosaki K, Kido J, Yoshida S, Sugawara K, Miyamoto T, Inoue T, et al. Newborn screening for Pompe disease in Japan: report and literature review of mutations in the GAA gene in Japanese and Asian patients. J Hum Genet. 2019;64:741-55. https://doi.org/10.1038/s10038-019-0603-7.

13. Niño MY, Groen SLM, Bergsma AJ, Beek NAME, Kroos M, HoogeveenWesterveld $M$, et al. Extension of the Pompe mutation database by linking disease-associated variants to clinical severity. Hum Mutat. 2019;40:1954-67.

14. Henrie A, Hemphill SE, Ruiz-Schultz N, Cushman B, DiStefano MT, Azzariti $D$, et al. ClinVar miner: demonstrating utility of a web-based tool for viewing and filtering ClinVar data. Hum Mutat. 2018;39:1051-60. https://doi. org/10.1002/humu.23555.

15. Faria DOS, Groen SLM, Hoogeveen-Westerveld M, Niño MY, Ploeg AT, Bergsma AJ, et al. Update of the Pompe variant database for the prediction of clinical phenotypes: novel disease-associated variants, common sequence variants, and results from newborn screening. Hum Mutat. 2021:42:119-34.

16. Desmet F-O, Hamroun D, Lalande M, Collod-Béroud G, Claustres M, Béroud C. Human splicing finder: an online bioinformatics tool to predict splicing signals. Nucleic Acids Res. 2009;37:e67. https://doi.org/10.1093/ nar/gkp215.

17. Labrousse P, Chien YHH, Pomponio RJ, Keutzer J, Lee NCC, Akmaev VR, et al. Genetic heterozygosity and pseudodeficiency in the Pompe disease newborn screening pilot program. Mol Genet Metab. 2010;99:379-83.

18. Lee D-H, Qiu W-J, Lee J, Chien Y-H, Hwu W-L. Hypertrophic cardiomyopathy in Pompe disease is not limited to the classic infantile-onset phenotype. JIMD Rep. 2014;17:71-5.

19. Tang H, Feuchtbaum L, Sciortino S, Matteson J, Mathur D, Bishop T, et al. The first year experience of newborn screening for Pompe disease in California. Int J Neonatal Screen. 2020;6:9.

20. Burton BK, Charrow J, Hoganson GE, Fleischer J, Grange DK, Braddock SR, et al. Newborn screening for Pompe disease in Illinois: experience with 684,290 infants. Int J Neonatal Screen. 2020;6:4.

21. Ficicioglu C, Ahrens-Nicklas RC, Barch J, Cuddapah SR, DiBoscio BS, DiPerna JC, et al. Newborn screening for Pompe disease: pennsylvania experience. Int J Neonatal Screen. 2020;6:89.

22. Su X, Sheng H, Huang Y, Li X, Zhang W, Zhao X, et al. Clinical and GAA gene mutation analysis in 21 Chinese patients with classic infantile pompe disease. Eur J Med Genet. 2020;63:103997.

23. Chen X, Liu T, Huang M, Wu J, Zhu J, Guo Y, et al. Clinical and molecular characterization of infantile-onset Pompe disease in mainland chinese patients: identification of two common mutations. Genet Test Mol Biomark. 2017;21:391-6.

24. Shieh J-J, Lin C-Y. Identification of a small deletion in one allele of patients with infantile form of glycogen storage disease type II. Biochem Biophys Res Commun. 1996;219:322-6.

25. Klug TL, Swartz LB, Washburn J, Brannen C, Kiesling JL. Lessons learned from Pompe disease newborn screening and follow-up. Int J Neonatal Screen. 2020;6:11.

26. Tsujino S, Huie M, Kanazawa N, Sugie H, Goto Y, Kawai M, et al. Frequent mutations in Japanese patients with acid maltase deficiency. Neuromuscul Disord. 2000;10:599-603.

27. Chien YH, Lee NC, Huang HJ, Thurberg BL, Tsai FJ, Hwu WL. Later-onset pompe disease: early detection and early treatment initiation enabled by newborn screening. J Pediatr. 2011;158:1023-7. 
28. Chien Y-H, Hwu W-L, Lee N-C. Newborn screening: Taiwanese experience. Ann Transl Med. 2019;7:281-281.

29. Peruzzo P, Pavan E, Dardis A. Molecular genetics of Pompe disease: a comprehensive overview. Ann Transl Med. 2019;7:278-278.

30. Liao H-C, Chan M-J, Yang C-F, Chiang C-C, Niu D-M, Huang C-K, et al. Mass spectrometry but not fluorimetry distinguishes affected and pseudodeficiency patients in newborn screening for Pompe disease. Clin Chem. 2017:63:1271-7.

31. Smith LD, Bainbridge MN, Parad RB, Bhattacharjee A. Second tier molecular genetic testing in newborn screening for pompe disease: landscape and challenges. Int J Neonatal Screen. 2020;6:32.

32. Carrasco-Rozas A, Fernández-Simón E, Lleixà MC, Belmonte I, PedrosaHernandez I, Montiel-Morillo E, et al. Identification of serum microRNAs as potential biomarkers in Pompe disease. Ann Clin Transl Neurol. 2019;6:1214-24.

33. Tarallo A, Carissimo A, Gatto F, Nusco E, Toscano A, Musumeci O, et al. microRNAs as biomarkers in Pompe disease. Genet Med. 2019;21:591600. https://doi.org/10.1038/s41436-.

34. Manwaring V, Prunty H, Bainbridge K, Burke D, Finnegan N, Franses R, et al. Urine analysis of glucose tetrasaccharide by HPLC; a useful marker for the investigation of patients with Pompe and other glycogen storage diseases. J Inherit Metab Dis. 2012;35:311-6. https://doi.org/10.1007/ s10545-011-9360-2.

35. Young SP, Piraud M, Goldstein JL, Zhang H, Rehder C, Laforet P, et al. Assessing disease severity in Pompe disease: the roles of a urinary glucose tetrasaccharide biomarker and imaging techniques. Am J Med Genet Part C Semin Med Genet. 2012;160:50-8. https://doi.org/10.1002/ ajmg.c.31320.

36. Yoshida S. Genetic testing of lysosomal storage diseases by next generation sequencer. Sci Rep Chemo-Sero-Therap Res Inst. 2015;24:14-31.

37. Adzhubei I, Jordan DM, Sunyaev SR. Predicting functional effect of human missense mutations using PolyPhen-2. Curr Protoc Hum Genet. 2013;76:7201-72041. https://doi.org/10.1002/0471142905.hg0720s76.

\section{Publisher's Note}

Springer Nature remains neutral with regard to jurisdictional claims in published maps and institutional affiliations.

Ready to submit your research? Choose BMC and benefit from:

- fast, convenient online submission

- thorough peer review by experienced researchers in your field

- rapid publication on acceptance

- support for research data, including large and complex data types

- gold Open Access which fosters wider collaboration and increased citations

- maximum visibility for your research: over $100 \mathrm{M}$ website views per year

At BMC, research is always in progress.

Learn more biomedcentral.com/submissions 